\title{
EL CORO EN LA RENOVACIÓN TEATRAL DE CIPRIANO RIVAS CHERIF
}

\section{THE CHORUS IN THE THEATRICAL RENOVATION BY CIPRIANO RIVAS CHERIF}

\author{
Jorge GARCÍA-RAMOS MERLO
}

\author{
Universidad Internacional Menéndez Pelayo \\ jorgegarmerlo@yahoo.es
}

\begin{abstract}
Resumen: Cipriano Rivas Cherif (1891-1967) representa la dirección de escena renovadora en el teatro español del primer tercio del siglo xx. En sus proyectos teatrales y puestas en escena reincorpora diversos elementos corales (musicales, plásticos, populares, rituales...), mostrándose como un director de teatro total. Para ello tendrá como referencia las modernas corrientes del teatro europeo, que él tanto conocía. La técnica coral coadyuva a conseguir un espectáculo de arte y una mayor comunicación con el público en el teatro. Destacará su colaboración con Valle-Inclán y García Lorca, los dos mayores autores de este teatro coral renovador en España.
\end{abstract}

Abstract: Cipriano Rivas Cherif (1891-1967) represents the renovating stage direction in the Spanish theater of the first third of the twentieth century. In his theatrical projects and staging he rejoins various choral elements (music, plastic, popular, rituals...), showing himself as a total 
theater director. For it he will have as reference the currents of modern European theater, which he so much knew. The coral technique contributes to an art show and more communication with the public in the theater. It will be very noteworthy his collaboration with Valle-Inclán and Garcia Lorca, the two major authors of this coral-renovating theater in Spain.

Palabras clave: Teatro. Coro. Rivas Cherif. Director de escena. Renovación.

Key words: Theater. Chorus. Rivas Cherif. Stage director. Renovation.

«El coro es algo insustituible, algo tan profundamente teatral, que su exclusión no la concibo.»

Federico García Lorca (La Libertad, 24-XII-1930).

\section{EL CORO EN EL TEATRO Y SU RESURGIMIENTO EN EL PRIMER TERCIO DEL S. XX}

\subsection{El coro en el teatro}

Apenas se ha estudiado la relevancia que tiene el coro como elemento renovador del teatro durante el primer tercio del siglo XX en España y en Europa (García-Ramos, 2012). El teatro nace del coro en el ditirambo dionisíaco, constituyendo la expresión dramática, ritualizada y musical del pueblo. Como dice Aristóteles en su Poética (cap. 18), el coro es ante todo un personaje, pero además también configura y determina una dramaturgia a través de sus variadas formas y funciones dramáticas (poética, musical, ritual, crítica, metateatral, escénica...).

La tragedia griega transformaba el texto dramático, de naturaleza mítica, en una representación coreográfica y musical, creando un espectáculo total. El coro era el encargado de la parte musical, con los cantos («choreúein», cantar) y las danzas («orcheisthai», danzar), que variaban según el ritual que se celebrara (emmeleia para las danzas graves y solemnes de los estásimos de la tragedia; hyporquema, para los triunfos o celebraciones festivas; kordax, para las desinhibiciones de la comedia). Por tanto, además del texto y los personajes, el coro introducía otros rasgos constitutivos del teatro como son el gesto y el ritmo del conjunto escénico. Estas cualidades, propias del coro griego, son las que precisamente van a querer recuperar los directores de escena renovadores del primer tercio del siglo xx, entre ellos Rivas Cherif. 
Cuando Nietzsche, en El nacimiento de la tragedia griega, aboga por la vuelta a la tragedia griega más pura, la de Esquilo, con ello ya está planteando las bases para la renovación del drama contemporáneo. El regreso de la música y la poesía a la escena teatral compondrán su núcleo. En este aspecto será determinante la influencia, a comienzos del siglo xx, de Nietzsche y Wagner, con su teoría del drama musical y del teatro total («Gesamtkunstwerk»). En la teoría teatral de la época las referencias serán inacabables: Adolphe Appia, Gordon Craig, Hugo Ball, Antonin Artaud, etc. Esta influencia también la podemos ver en Valle-Inclán, quien junto a García Lorca representa el teatro más renovador en España y, no casualmente, también el más coral. Con ambos autores tendrá Rivas Cherif una firme afinidad teatral que se plasmará también en una efectiva colaboración (Aguilera Sastre y Aznar Soler, 1999: 231-268).

Los dramaturgos renovadores, tanto directores como autores, vuelven a fijar la atención en los teatros más corales (tragedia griega, teatro religioso medieval y clásico, teatro lírico y musical, etc.), considerándolos como referencias revitalizadoras de la nueva escena teatral. El coro, pues, también se encuadra dentro de la simbiosis entre tradición y vanguardia que domina la producción artística del primer tercio del s. xx.

\subsection{La adecuación y pertinencia del coro en la corriente renovadora del teatro en el primer tercio del s. XX}

Son muchos los motivos históricos y teatrales que favorecen esta vuelta del coro a la escena dramática a principios del XX. Históricamente nos encontramos ante una profunda transformación de la sociedad, en la que acontece una irrupción de las masas. La colectividad adquiere nuevo protagonismo, tal como apunta Ortega y Gasset en La rebelión de las masas (1930): «La muchedumbre, de pronto se ha hecho visible, se ha instalado en los lugares preferentes de la sociedad. Antes, si existía, pasaba inadvertida, ocupaba el fondo del escenario social; ahora se ha adelantado a las baterías, es ella el personaje principal. Ya no hay protagonistas: solo hay coro» (Ortega y Gasset, 1985: 67).

Similar observación hace Valle-Inclán cuando habla de una nueva forma de hacer literatura, en la que la colectividad y la multitud sustituyen al individuo, pasando a ocupar ahora el centro de atención: «Ha dejado de interesarnos el individuo, al menos se ha borrado el primer término, ante el interés mayor que despiertan en nosotros las colectividades, la Nación, el hecho social» (Fuentes, 1980: 123). 
Surge ahora un nuevo tipo humano y social: «el hombre-masa». Este ocupará el protagonismo en los acontecimientos políticos (huelgas, revoluciones, totalitarismos, etc... ) y también se hará visible en el teatro, presentándose en una escena coral (teatro revolucionario ruso -Maiakovski-, teatro social y político alemán —expresionistas, Brecht, Piscator-, iniciativas de teatro popular en Francia - Firmin Gémier, Jacques Copeau- o en España — La Barraca. Misiones Pedagógicas—, etc.).

A menudo, estas nuevas manifestaciones teatrales también recurrirán a la técnica coral como medio de comunicación más directa con el público. La vieja parábasis de la comedia griega de Aristófanes (el corifeo se quitaba la careta y se dirigía al público de frente) encuentra ahora su trasunto en los coros del teatro épico brechtiano o en los prólogos corales que vuelven a estar presentes en muchas obras (García Lorca).

Los dramaturgos renovadores de comienzos del XX (Adolphe Appia, Gordon Craig, Max Reinhardt, Meyerhold, Jacques Copeau, etc.), entre los que se encuentra Rivas Cherif, vuelven a tener en cuenta los elementos corales que estaban presentes en el teatro antiguo: la música (danza y canto), el rito (el componente mítico y religioso) y el pueblo (el nuevo público). Revalorizan la idea del teatro como espectáculo, tomando como referentes la tragedia griega y los clásicos - especialmente Shakespeare y los autores del Siglo de Oro español-, en busca de un teatro más auténtico y vivo frente a otro que consideraban ya decadente y acartonado, de diálogo convencional y escenificación naturalista.

Se trata, por tanto, de sustituir una técnica dramática ya agotada en el personaje, el diálogo y el escenario de la caja italiana. Es entonces cuando la dramática coral del teatro se presenta como alternativa renovadora. La crisis del teatro a comienzos del s. XX convergerá con el coro en cuatro puntos fundamentales:

1. El personaje. De un personaje individual, concreto y personalizado, se pasa a un nuevo personaje colectivo, abstracto o popular. Este cambio se integra dentro de la nueva estética de las vanguardias artísticas de la época, en las que los rasgos individuales, personales y concretos son sustituidos por unos rasgos difuminados en una abstracción universal y colectiva, cuando no deshumanizada. Así ocurre en el teatro simbolista, en el expresionista, $\mathrm{y}$ en el teatro social.

2. El lenguaje dramático. Se produce la controversia «espectáculo versus texto». Frente al diálogo de tradición clasicista francesa se recurre a una 
expresión musical, una poesía dramática, una reteatralización (el elemento artístico en el teatro) e incluso un lenguaje inarticulado, como ocurre en el expresionismo y en el surrealismo.

3. El espacio escénico. Hay una continua experimentación de nuevos escenarios frente a la «caja italiana»: plazas públicas, teatros romanos, circos, plazas de toros, etc... Se suele acudir a espacios abiertos y circulares, que se asemejan a la orkhestra del coro en el teatro griego, frente al teatro cerrado y rectangular. Las nuevas propuestas del teatro ruso (Meyerhold, Evreinov, Ojlopkov) y alemán (Max Reinhardt, la Bauhaus) ya lo están llevando a cabo por estos años.

4. El público. Hay una preocupación permanente por encontrar un nuevo público, más popular, heterogéneo y activo, frente al público burgués urbano. Se trata de recuperar el vínculo entre escena y público, que en los teatros más ritualizados y populares de la historia era representado por la presencia del coro (tragedia griega, misterios,...). De ahí el interés por un teatro popular que muchas veces deriva en teatro social y político. El coro representa esta cultura que se manifiesta a través de la voz anónima y colectiva del pueblo (cancioneros, romances, etc.).

Diversos críticos, teóricos, ensayistas, directores de escena y autores dramáticos renovadores coinciden en considerar estos puntos mencionados como referencia ineludible para conseguir la tan repetida y ansiada renovación del teatro. Dentro de este grupo se encuentra en un lugar destacado Cipriano Rivas Cherif. Él será el que muestre más iniciativa y vigor para realizar en España la tan buscada revitalización del teatro, acudiendo para ello a estos elementos corales.

La vieja función del coro como medio de enlace entre los personajes principales, situados en el proscenio, y el público, situado en las gradas o el patio de butacas, vuelve a estar presente en diferentes formas. Esta voluntad de comunicación directa, encaminada a suprimir en muchas ocasiones la ilusión dramática y las candilejas, encuentra su realización teatral en una técnica coral. La crítica sociopolítica del teatro épico (Brecht, Piscator), la propaganda revolucionaria del teatro ruso (Maiakovski), la experimentación con el espacio escénico (Meyerhold, Bauhaus) y el metateatro de Pirandello y Lorca, son buenas muestras de ello. 


\section{RIVAS CHERIF Y LA FIGURA DEL DIRECTOR DE ESCENA RENOVADOR: INFLUENCIAS EUROPEAS}

\subsection{La nueva figura del director de escena. Hacia una puesta en escena coral}

Rivas Cherif representa en España el papel renovador que ejercían en Europa los nuevos directores de escena: Gordon Craig en Inglaterra, Jacques Copeau en Francia, Max Reinhardt en Alemania o Stanislavski y Meyerhold en Rusia. Los antecedentes de Martínez Sierra, Adrià Gual, José Francés o Ricardo Baeza, en busca de un teatro español más moderno y artístico, no llegaron a suponer una completa renovación escénica. Esta renovación pasaría por la labor de un director que revitalizara la puesta en escena con elementos complementarios al texto dramático, entre ellos se encontrarían los coros. Una concepción coral de la puesta en escena era oportuna para reanimar un teatro español que se había encerrado en un salón con mesa camilla.

Además, las propuestas teatrales que venían de Europa cada vez estaban más cerca. Críticos como Luis Araquistáin, Enrique Díez-Canedo, Melchor Fernández Almagro, Rafael Marquina, Enrique de Mesa, Arturo Mori, Manuel Pedroso, J.G. Olmedilla, Antonio Espina, José Francés, Juan Chabás, Ramón J. Sender y Cipriano Rivas Cherif defendían la idea de un teatro con una mayor riqueza escénica, muy diferente a la abundancia de atrezzo del teatro naturalista. La calidad literaria y el espectáculo se verían conjuntados a través de elementos de integración como el coro, en el que confluían la música, la poesía y el pueblo.

Cipriano Rivas Cherif representará la culminación de esta corriente de aceptación del director de escena en el teatro español de comienzos del siglo XX. Aun así, el retraso en el que estaba el teatro español con relación al teatro europeo era evidente en este tema, tal como reconoce la crítica teatral (Dougherty y Vilches, 1997: 230; Araquistáin, 1930: 257).

Esta necesidad de un director de escena se hace especialmente necesaria en una concepción coral del teatro, en donde es preciso un coordinador de todos los elementos que han de desarrollarse sobre el escenario. La inclusión de lo musical y lo plástico en este teatro vanguardista, con el ritmo como componente fundamental, supone una complejidad coreográfica que ha de ser dirigida. Por ello, la figura del director de escena va intrínseca- 
mente unida a un concepto de teatro coral, en donde lo colectivo prima sobre lo individual.

Rivas Cherif así lo entiende, pero es consciente de las limitaciones técnicas que se encuentra en el teatro español de su tiempo. Al referirse a los medios escénicos que tienen los directores europeos, en contraste con los se pueden encontrar en España, pone como ejemplo el coro de hilanderas del Holandés errante en la puesta en escena de Max Reinhardt. La presencia del coro marca el grado de estructuración escénica:

Reinhardt ha tenido a su disposición en Berlín y en Salzburgo cuantos medios mecánicos puede apetecer un director, y de que estaban dotados todos los modernos teatros alemanes: escenarios rotatorios o ascendentes y descendentes, de modo que puedan estar dispuestos tres decorados completos (y hasta con el coro de hilanderas del «Holandés errante» preparado ya en su telar) (Rivas Cherif, 1991: 324).

Rivas Cherif cree en esta función del director de escena como coordinador e integrador de diferentes artes que han de estar presentes en el teatro (música, pintura, danza...), siguiendo así a los nuevos directores europeos (Gordon Craig, Jacques Copeau, Reinhardt, Meyerhold) que buscaban una renovación del teatro a partir de esta idea de desarrollo coral para la escena (Copeau, 2002: 490). Adquieren especial interés la música, la danza y los conjuntos dentro de la plástica escenográfica (los retablos corales de ValleInclán son la muestra más destacada). La admiración de Rivas Cherif por Diaghilev, Manuel de Falla y los maestros de ópera hay que situarla en este contexto.

\subsection{La influencia de los directores de escena europeos en la dramaturgia coral de Rivas Cherif}

La vinculación de Rivas Cherif con el teatro renovador europeo de la época fue intensa, tal como demuestra en sus conferencias y escritos ( $\mathrm{La} \mathrm{Li}$ bertad, 4 de enero 1933: 5). Esta determinaría su acercamiento a un teatro coral que aplicará en la escena española y le llevará, incluso, a recibir el Premio Nacional de Literatura en 1931 por un estudio sobre el teatro contemporáneo extranjero, en el que recogía y analizaba las diferentes corrientes y tendencias teatrales que se estaban dando por aquellos años en Alemania, Inglaterra, Francia, Italia y Rusia (Sampelayo, 26 de diciembre, 1931: 11). 
El primer contacto que tiene Rivas Cherif con el teatro de vanguardia europeo tiene lugar en Italia, cuando cursa su doctorado de Derecho en Bolonia (1910-1914). Allí conoce la teoría teatral de Gordon Craig — por aquel tiempo está dirigiendo el Arena Goldoni en Florencia-, a través de sus escritos publicados en la revista The Mask ${ }^{1}$. Con la ópera y el teatro del director inglés, Rivas Cherif descubre un nuevo concepto teatral que rompe con el naturalismo escénico y el lenguaje dramático convencional, basado en la palabra dentro del diálogo. Se acerca a un teatro total, en el que la importancia de la plástica y el ritmo escénico propiciarán la presencia de grupos y coros sobre el escenario. El movimiento de los actores en escena, armonizados rítmicamente bajo un concepto colectivo y de conjunto de la escena, marcará una nueva forma de hacer teatro, con el apoyo de la escenografía y la música, siguiendo así el camino emprendido por Adolfo Appia, con la teoría wagneriana del Wort-Ton-Drama ${ }^{2}$.

Rivas Cherif reconocerá siempre esta primera influencia extranjera en el proyecto de renovación de la escena teatral española, hasta llegar a considerar a Gordon Craig como «el Renovador fundamental del teatro en el siglo que casi tiene de existencia, fue el hecho decisivo que determinó la definitiva perdición de mi vida por el teatro, y ni siquiera por el teatro comercial, por el artístico.» (Aguilera y Aznar, 1999: 19). En este contacto con el teatro europeo, Rivas Cherif no solo abre los ojos a un nuevo teatro, sino que también descubre la mediocridad del supuesto teatro renovador que se estaba realizando a comienzos de los años 20 en Madrid (Rivas Cherif, 21 de agosto, 1920: 11).

De igual modo, produce una impresión decisiva en Rivas Cherif su viaje a París, entre 1919 y 1920 (Rivas Cherif, 1979: 90-95): «era el de Copeau, reintegrado a su Vieux-Colombier después de su desengaño de Nueva York, el de los Pitoëff, el de la reaparición de la Duncan, el del estreno de «El sombrero de tres picos», de Falla, por los bailes rusos de Diaghilef, a quien

1 La ciudad de Florencia será el escenario ideal para los directores de escena más importantes de la época. Gordon Craig, Max Reinhardt y el Jacques Copeau utilizaron sus plazas y jardines para representar obras dirigidas por ellos. El maestro francés dirigió la puesta en escena de El Misterio de Santa Uliva (1933) y Savonarola (1935), ambas obras caracterizadas por el uso prioritario de los coros en un espacio al aire libre, el claustro de Santa Croce y la Piazza della Signoria, respectivamente.

2 El Wort-Tondrama es la nueva forma dramática que crea Richard Wagner, resultado de la conjunción de la palabra, la música, la danza y la pantomima. El creador escénico suizo, Adolphe Appia (1862-1928), es el gran teórico, como director de escena, de la concepción dramática wagneriana del teatro total. En su obra La música y la puesta en escena (1899) es donde emplea este término para explicar la propuesta renovadora de Wagner (Appia, 2000: 77-321). 
yo había conocido tres años antes en Madrid» (Rivas Cherif, 21 de enero, 1968). En la revista España publica una crónica rimada del exitoso estreno de «El sombrero de tres picos» en el «Théâtre National de l'Opéra» de París. En ella destaca la escena final de la obra, de gran riqueza coral, con la intervención de los Ballets Rusos de Diaghilev y plástica escenográfica de Pablo Picasso: «... surge la gente que contenta se alborota, el coro se levanta y la música revienta delirante en una jota; ¿y mientras que el canto brota, va poblando el escenario una procesión de Goya» (Rivas Cherif, 28 de febrero, 1920: 12-13).

En París entra en contacto con el teatro de Jacques Copeau, el gran renovador del teatro francés de vanguardia y firme defensor del coro dentro de la puesta en escena, como expone en sus escritos de teoría teatral (Copeau, 2002: 391-410). A pesar de ser francés, y no ruso o alemán, Copeau abogaba por una puesta en escena en la que el coro fuera un elemento prioritario, algo que tendrá en cuenta Rivas Cherif para sus trabajos como director de escena. Copeau, desde su teatro escuela el Vieux Colombier, indicó el camino a Rivas Cherif para su proyecto del Teatro Escuela de Arte, en 1920 (Rivas Cherif, 16 de marzo, 1921: 3). También en París conocerá a Gaston Baty — dado a conocer en España por Azorín en varios artículos-, quien dentro de su concepto antinaturalista de la escena promovía la utilización de medios expresivos procedentes de la tragedia griega, los misterios medievales y el drama isabelino.

El ejemplo del Teatro de Arte de Moscú había hecho ver que los coros y los bailes rusos de Diaghilev formaban parte de una nueva escenografía. Los experimentos de Adolphe Appia ya habían señalado el camino, al combinar el ritmo con la luz. La Rítmica del conjunto escénico pasa a ocupar un primer plano en la puesta en escena, tal como promulga Jacques-Dalcroze en su Gimnasia rítmica, que tanta influencia ejercería en Copeau para su Vieux-Colombier. Estas fuentes son las que recibirá Rivas Cherif para su proyecto de renovación teatral en España.

Todas las nuevas iniciativas renovadoras que se estaban llevando a cabo en el teatro europeo iban encaminadas hacia un teatro coral: composición plástica y musical de la escena, caracterización general o colectiva de los personajes, colocación e intervención de los actores sobre el escenario, ruptura de barreras entre el escenario y el público, integración activa del público en el espectáculo, vuelta a la dramaturgia del teatro antiguo, etc. Rivas Cherif las atribuye a las vanguardias teatrales del momento, en su artículo «Divagación a la luz de las candilejas», de 1920 (Sánchez, 1999: 438-445). 
El nuevo mundo coral del que hablaba Ortega y Gasset irrumpe en la escena a través del teatro popular y el teatro de masas. Firmin Gémier montaría en el Circo de Invierno de París (1911) el Edipo, rey de Tebas, en donde se congregaron más de doscientos figurantes y miles de espectadores. Estas puestas en escena corales, muchas veces próximas a un teatro de masas, habría que encuadrarlas en un tipo de teatro social que tendrá relación con las Fiestas del Pueblo, organizadas en París, con los «coros de obreros» y la orquesta de Doyen.

Rivas Cherif aprenderá de todas estas iniciativas, así como de las representaciones de masas de Rusia y Alemania ${ }^{3}$, para luego realizar su proyecto teatral renovador en España. Sus puestas en escena a cielo descubierto (la Chopera del Retiro, el Teatro Romano de Mérida y la Plaza de Toros de Las Ventas) constituirán un teatro artístico y popular.

El otro director de escena europeo que influirá especialmente en Rivas Cherif será el austriaco Max Reinhardt, al que conocerá en un viaje a Alemania en febrero de 1933, en donde le propone venir a Madrid en octubre de ese mismo año para dirigir La muerte de Dantón de Büchner ( $L a$ Voz, 1 de marzo, 1933: 4; El Sol, 2 de marzo, 1933: 8; El Sol, 13 de marzo, 1933: 5). Allí verá el resultado del trabajo escénico que realiza con obras corales de gran despliegue humano y técnico, en donde destaca el desarrollo de los agrupamientos en escena, al modo del teatro de masas. De él aprenderá el tratamiento de los grupos sobre el escenario, su precisa evolución y armonización, para conseguir un completo aprovechamiento de las posibilidades escénicas que ofrece el espacio teatral. Así lo plasmará Rivas Cherif en las puestas en escena que realiza de Medea y Elektra, en el Teatro Romano de Mérida, y de El alcalde de Zalamea, en la madrileña plaza de toros de Las Ventas.

La idea es escenificar la comedia de Calderón en un espacio circular, tal como había presentado el director vienés ya antes en un circo. Pero en este caso la intención será realizarla en una plaza de toros (Rivas Cherif, 13 de abril, 1934: 6). Se trataría de una puesta en escena plenamente coral, que recordaría al teatro griego ya no solo en cuanto al espacio y a los actores, sino también en cuanto a la posición del público (Aguilera y Aznar, 1999: 39).

3 Rivas Cherif muestra especial interés por las propuestas de un teatro popular que se están llevando a cabo en Alemania (la Volksbüne o Teatro del Pueblo y el de la Kurffurten Damen), algo que ya había visto antes en Francia y que constituirá uno de sus objetivos más deseados para desarrollar en la escena teatral española (Rivas Cherif, 19 de abril, 1933: 1). 
También reconoce en el director austriaco el redescubrimiento de espacios escénicos propios de un teatro antiguo, más cerca de la forma coral: «Max Reinhardt ha roto varias veces los límites, que parecía invulnerables, del escenario, interrumpiendo las tradiciones teatrales de tres siglos para restaurar normas de tradición más antigua: ha dispuesto las localidades en anfiteatro; ha representado a Shakespeare en libertad, en la relativa libertad de un circo, en medio de la pista, y no encuadrado en el marco de la escena» (Rivas Cherif, 9 de mayo, 1928: 10-11).

Rivas Cherif creía que el teatro de Valle-Inclán podría adecuarse muy bien a la dramaturgia escénica de Reinhardt. En ambas se difuminaban las individualidades en favor del conjunto, para lograr así su mayor rendimiento dramático y plástico. Por eso, al hablar del teatro español en el extranjero, llega a anunciar que el director austriaco va a montar uno de los dramas del gallego. No consta que llegara a realizarlo, pero un teatro coral como el de Valle-Inclán, considerado «irrepresentable» en España, podría encontrar su aprovechamiento en una puesta en escena de Reinhardt.

Siempre tuvo Rivas Cherif una relación cercana con el teatro ruso, por razones teatrales y políticas ${ }^{4}$. Además de suponer un referente principal para su dramaturgia, promueve su conocimiento en España con la presentación del Teatro de Arte de Moscú, que representará varias obras del teatro ruso contemporáneo con la actriz Vera Gretch (El Sol, 8 de marzo, 1932: 2). El teatro ruso, de naturaleza coral, estará emparentado con el montaje que realiza Rivas Cherif de Fuenteovejuna, tal como refiere Antonio Espina:

El dramaturgo supo incorporar a la escena con genial visión del futuro ese personaje tan de nuestro tiempo que llamamos la «masa». Esta circunstancia determina que la idea de Fuenteovejuna sea totalmente moderna. Así se explica el éxito que la famosa comedia dramática de Lope obtuvo en Moscú cuando la dio a conocer el gran actor y escenógrafo Stanislawsky, y también cuando la montó hace tres años en Alemania el ruso Meyerhold, que antes había traducido el Peribáñez para su teatro del pueblo (El Sol, 24 de marzo, 1935: 2).

4 Recordemos el viaje que realizó a Moscú en septiembre de 1937 para acudir al Festival Internacional de Teatro, encabezando la delegación de la que formaban parte Enrique Casal, Miguel Hernández, Miguel Prieto y Gloria Santullana. Las impresiones del viaje serán publicadas en un artículo ( $L a$ Vanguardia, 21 de diciembre, 1938: 3). 
Meyerhold propone la abolición de las candilejas en su Teatro de la Convención, así como la distribución simétrica de los grupos (comparsas y coros) en escena. Busca que el nuevo teatro recupere la intensidad dramática que ha perdido, y para ello intenta recuperar el sentido ritualizado del teatro antiguo. De ahí parte también la reutilización del coro, con los recursos corporales y musicales que le son propios (Meyerhold, 1992: 172-177). A ello hay que unirle la voluntad de suprimir las candilejas, que lleva a experimentar con otros espacios escénicos cercanos al teatro coral (Meyerhold, 1998: 56, 193-194).

Rivas Cherif nos habla de la fuerte impresión que le causó al maestro ruso el montaje de El alcalde de Zalamea en una plaza de toros: "Veinte mil espectadores en torno a una pista escénica o escenario circular, era más de lo que el propio Meyerhold se proponía con la construcción de un teatro adecuado a su intención pro masas, en cierto modo inspirado en los teatros griegos y romanos» (Rivas Cherif, 1991: 263-264). La dirección de escena tendría que superar la dificultad de introducir en el escenario una numerosa comparsería de doscientos figurantes, con incluso caballos dentro del escenario, tal como cuenta el propio director madrileño (Rivas Cherif, 13 de abril, 1934: 6). Las puestas en escena, al aire libre, del teatro de masas ruso (Meyerhold, Evreinov, Ojlopkov...) serían un buen referente orientativo ${ }^{5}$. Rivas Cherif también encuentra varias coincidencias entre el teatro coral griego y la corrida de toros, al igual que Ortega y Gasset y Valle Inclán: la forma circular de la orquestra y del ruedo, el rito sacrificial, la música, la visión participativa del público y la gran riqueza semiológica del espectáculo. En el libro Cómo hacer teatro dedica un epígrafe a la fiesta de los toros («Teatros de sol y sombra, de la naturaleza y del artificio») como referencia válida para el teatro (Rivas Cherif, 1991: 263-268).

En los nuevos directores de escena europeos encuentra Rivas Cherif las condiciones para realizar una dramaturgia total que supere el lenguaje plano

5 También la crítica destacó esta presentación coral, propia de un teatro de masas, que hizo Rivas Cherif de la comedia calderoniana. Así por ejemplo, Manuel Machado la ve muy oportuna, dentro de esa vinculación entre el pueblo tradicional español y el teatro de masas moderno: «Las figuras principales de la obra y los conjuntos de aldeanos y soldados que en ella intervienen parecían moverse allí como en la verdadera realidad, y el pueblo y el campo [...] fondo de la maravilla calderoniana que es El alcalde de Zalamea, se investían de personalidad y protagonismo. Es un notable - y loable — ensayo de teatro para masas..." (La Libertad, 15 de abril, 1934: 4). Todo este reparto multitudinario sería completado por los alumnos de la TEA, quienes junto a la comparsería de doscientos figurantes, el acompañamiento de la banda de música y la interpretación de canciones del maestro Chapí, conformarían un auténtico espectáculo, propio del teatro total que tanto apreciaba Rivas Cherif. La influencia de los nuevos directores de escena europeos (Reinhardt, Craig, Meyerhold) está claramente presente en esta realización. 
del melodrama. De ahí surge también el interés por recuperar la fuerza espectacular y ritual que tenía el teatro antiguo, de naturaleza coral. La conferencia dada en la Residencia de Estudiantes por el director italiano futurista, A.G. Bragaglia, que fue presentado en la prensa como el más revolucionario de Italia, incide en esta importancia del concepto de espectáculo en el teatro moderno (Heraldo de Madrid, 7 de diciembre, 1928: 7).

\section{EL CORO EN LA ACTIVIDAD TEATRAL DE RIVAS CHERIF}

En la labor teatral de Rivas Cherif en España, tanto en sus proyectos teatrales (Teatro de la Escuela Nueva, El Caracol, Teatro Romano de Mérida, Teatro Español, Teatro de la Escuela de Arte), como en sus puestas en escena (clásicos grecolatinos, clásicos españoles, teatro extranjero contemporáneo, colaboraciones con Valle-Inclán y García Lorca), veremos la aplicación de este nuevo concepto de teatro coral que procedía de las corrientes renovadoras europeas.

Esta dramaturgia coral en Rivas Cherif se manifestará a través de tres elementos que son consustanciales al coro desde sus orígenes: el musical, el popular y el ritual.

\subsection{El elemento musical}

El camino emprendido por Appia, Craig y Diaghilev reforzará a Rivas Cherif su voluntad de realizar un tipo de teatro total en el que la danza, la expresividad gestual de todo el cuerpo y el movimiento de los grupos pasarán a ser fundamentales. Ello se reflejará años más tarde en las puestas en escena de las obras lorquianas presentadas en el Teatro Español, así como en la recuperación del teatro clásico español, en especial el de Lope de Vega. A esto habría que añadir el nuevo florecer en los años 20 y 30 de los géneros musicales en el teatro (zarzuela, revista, opereta, variedades), que también influirán en la presencia de una escena coral de raíz musical. Como apunta M. ${ }^{\mathrm{a}}$ Carmen Gil Fombellida:

El interés de Rivas Cherif por el baile y por los géneros musicales quedará demostrado durante toda su trayectoria profesional. Escribe libretos para ballet e incluye piezas musicales y escenas de danza en sus montajes, tanto en obras clásicas como Fuenteovejuna (1935), La dama boba (1935), Medea $y$ Elektra (1933-1934), como en textos contemporáneos tales como 
La zapatera prodigiosa, Yerma (1934), Bodas de sangre (1935), etcétera. Incluso llegará a aceptar, en un reto complicado, la dirección del Teatro Lírico Nacional, con unas funciones en las que el movimiento de grupos en escena y el nuevo tratamiento de los coros llamarán la atención de la crítica especializada (Gil Fombellida, 2003: 27-28).

Rivas Cherif se siente desde joven atraído por el género lírico. Disfruta de la ópera en su estancia juvenil en Italia (1910-1914). De vuelta a España también se hace un apasionado de la zarzuela, a la que considera una referencia ineludible para el teatro renovador (Rivas Cherif, 1991: 56 y ss.), superando su atadura al teatro costumbrista de la época (Pedraza Jiménez, 2011: 105-114).

Como instructor de teatro, Rivas Cherif da especial importancia a la formación del actor integral, siguiendo así el planteamiento de los directores de escena europeos más importantes (la Supermarioneta de Gordon Craig, la Biomecánica de Meyerhold, etc.). El nuevo actor ha de recuperar las cualidades del coreuta del teatro griego, provisto del canto y la danza para su interpretación. Ya no solo ha de declamar bien, además de la palabra ha de perfeccionar las técnicas corales: «cúmplele ejercitarse en la gimnasia rítmica. Los elementos del baile han de iniciarle, asimismo, con las nociones primeras del canto» (Rivas Cherif, 1991: 135). De este modo, seguirá para la formación de sus actores del Teatro Escuela Nueva (1920) y el Teatro Escuela del Arte (1934) la pedagogía coral de la Gimnasia rítmica de Jacques-Dalcroze, que enlaza con Adolphe Appia y Jacques Copeau.

Ortega y Gasset encomia los ballets rusos de Diaghilev en su artículo escrito en 1921, Elogio al murciélago (Ortega, 1966: 123), poniéndolos como ejemplo para relanzar un teatro renovador y artístico, en el que el elemento musical y plástico de la danza enriquezca el espectáculo teatral, más allá del texto. También Rivas Cherif reconoce a la danza como parte principal de la escena dramática renovadora, tal como ocurría con el coro en el antiguo teatro griego. El baile deja de ser una expresión artística circunscrita al género musical, de ahí la inclusión de la danza española en el teatro español, con la Argentina y la Argentinita ${ }^{6}$, que siguen un tipo de teatro dionisíaco de corte artístico que ya se estaba realizando en Europa (Rivas

6 Rivas Cherif recuerda el aspecto dionisíaco de la «bailaora flamenca», que, como ménade desligada de su viejo coro de Dyonisos, acude ahora a los teatros para devolver el carácter expresivo y poético que tuvo antaño la escena dramática y que nunca debió perder: «Esa bailarina en quien el sagrado delirio de la danza ofrecida a Dyonisos se contempla con la euritmia y serena razón apolíneas...» (Los Lunes de El Imparcial, 5 de marzo, 1922; en Aguilera y Aznar, 1999: 143). 
Cherif, 1920, agosto, 113-119; Sánchez, 1999: 439-440). Así lo vemos en las danzas corales expresionistas de Mary Wigman y en las danzas dionisíacas de Georg Fuchs o de Isadora Duncan.

Por tanto, no es casual que fuese precisamente Cipriano Rivas Cherif, el hombre más renovador del teatro español del primer tercio del siglo xx, quien acudiese con más interés a las dos «Argentinas», en obras como $E l$ fandango de candil, El contrabandista — con «La Argentina»—o La romería de los cornudos — con «La Argentinita» y en colaboración con García Lorca- (Aguilera y Aznar, 1999: 66-68, 141 y ss.). Rivas Cherif seguía así las nuevas tendencias del teatro europeo al incorporar la danza en el teatro dramático, tal como decía Oskar Schlemmer - miembro destacado de la Bauhaus de Weimar en los años 20 y creador del ballet triádico- en sus Escritos de arte: «La danza teatral puede ser un nuevo punto de partida para la renovación» (Dougherty y Vilches, 1992: 144).

En este apartado será extraordinaria la colaboración que lleva con García Lorca. El poeta granadino representa la expresión artística más destacada de este tipo de teatro renovador que incluye la danza y el canto. En sus obras dramáticas surgen frecuentemente las escenas corales, realizando una función dramática principal (Mariana Pineda, La zapatera prodigiosa, Bodas de sangre, Yerma, El público...).

Rivas Cherif crea con Lorca el ballet titulado La romería de los cornudos (1927), representado finalmente por la Compañía de Bailes Españoles de La Argentinita, el 9 de noviembre de 1933 en el Teatro Calderón de Madrid, con música de Gustavo Pittaluga. Federico conoció muy de cerca los montajes del grupo teatral de Rivas Cherif, El Caracol, y ello también pudo influir en su actividad teatral; tal como se puede observar entre los montajes del Orfeo, de Cocteu, y Un sueño de la razón, de Rivas Cherif —realizados por $\mathrm{El} \mathrm{Ca-}$ racol_- y El público de García Lorca (Millán Jiménez, 1988: 87-91).

De ahí surgió la idea de programar el Amor de don Perlimplín, con la versión de cámara del «Aleluya erótica», que finalmente no se pudo representar. Sí se pudo representar en el Teatro Español la primera versión de $L a$ zapatera prodigiosa, el 24 de diciembre de 1930, a la que Lorca consideraría inferior con respecto a la versión estrenada en Buenos Aires, en 1933, por la compañía de Lola Membrives. Esta preferencia se debía principalmente a la mayor importancia que adquiría el aspecto coral de la obra, como el propio poeta reconoció: «Esta versión que da Lola Membrives de mi farsa, es la perfecta, es la que yo quiero. En ella hay música y bailes que no fue posible poner cuando el estreno en España» (Hernández, 2005: 159-162). 
Las limitaciones que había en el Teatro Español para presentar una puesta en escena verdaderamente coral quedan una vez más en evidencia, como ocurriera anteriormente con el montaje de Divinas palabras, realizado por Rivas Cherif ${ }^{7}$.

Asimismo, en el estreno de Yerma, en el Teatro Español (29 de diciembre de 1934), Rivas Cherif señaló como logro más importante de la puesta en escena los dos momentos de explosión coral de la obra:

Pocas veces se me ha dado conseguir un conjunto de actores, como para el coro de la romería, que guiaba Enrique García Álvarez [...]

No creo que pueda repetirse la escena de las lavanderas, que determinó desde luego el primer día el éxito clamoroso de Yerma, tal y como acertamos con aquel reparto de voces frescas, excelentemente acordadas y con tan segura entonación y bravo acento (Rivas Cherif, 24 de enero, 1965: 14; Aguilera y Aznar, 1999: 264).

El público había respondido bien ante las escenas más atrevidas, que eran precisamente las más corales, en especial la de la danza del Macho y la Hembra, en el acto III. El tratamiento artístico y vigoroso que realizó Rivas Cherif de estos dos momentos claves en la obra significaba una forma de reconciliación con sus principios de renovación de la puesta en escena, tras los fallidos intentos en el Español de Divinas palabras y, en menor medida, de La zapatera prodigiosa. Con esta dirección de Yerma, Rivas Cherif —al igual que Lorca - veía cómo era aceptada con agrado por el público español una nueva forma de llevar a escena el teatro, en la que el tratamiento coral constituía la parte principal. Mario Hernández comenta la impresión que produjo la puesta en escena de esta primera representación de Yerma, en la que fueron precisamente los episodios corales lo que más admiraron los presentes; tanto el coro de lavanderas como la danza dionisíaca del Macho y la Hembra, en la romería (Hernández, abril-junio, 1979: 304).

Igualmente, Díez-Canedo destacará el trabajo de dirección artística que realiza aquí Rivas Cherif, con especial atención al movimiento de grupos en las escenas del coro: «Los actores han entendido en general bien la interpre-

7 Su estreno en el Teatro Español de Madrid (16-XI-1933) implicaba un alto riesgo, como se demostró con la poca respuesta que tuvo. El propio Valle-Inclán era consciente de la dificultad de representar su obra: «Sin duda, está fuera de proporción para ser llevada a un escenario». A pesar de ello, la crítica destacó la dirección de comparsas y masas que realizó Rivas Cherif (Chabás, 17 de noviembre, 1933: 6). 
tación. [...] ¡Y cuán bien concertadas y a punto las escenas del coro. El autor, y el director artístico, Cipriano Rivas Cherif, han trabajado de veras» (Díez-Canedo, 31 de diciembre, 1934: 3; Aguilera y Aznar, 1999: 265).

Esta concepción coral de la escena dramática se refleja en el estreno de La calle, del norteamericano Elmer L. Rice (14-XI-1930). Frente a las dificultades para su puesta en escena, debido a las pequeñas dimensiones del escenario en el teatro Español, Rivas Cherif realiza una cuidadísima dirección de grupos junto a Margarita Xirgu, dando prioridad al ensayo de los movimientos y gestos del conjunto, consiguiendo armonizarlos en una interpretación coral (Gil, 2003: 190-95).

Rivas Cherif lleva a cabo una revisión de los clásicos españoles, presentándolos de una nueva manera. En ella los elementos corales, tanto musicales como plásticos, cumplirán la función de atraer de nuevo a un público acostumbrado a verlos en puestas en escena anodinas, viciadas por un diálogo falsamente engolado (Heraldo de Madrid, 21 de junio, 1935: 7). Para ello, Rivas Cherif recupera la frescura popular de Lope de Vega, alejándose del retoricismo clasicista y decimonónico. Con motivo de la representación de El villano en su rincón expresa su manera moderna de interpretar a los clásicos, destacando en ella los efectos plásticos y musicales, con la danza (La Voz, 1 de junio, 1935: 3; Aguilera y Aznar, 1999: 271).

Para el tricentenario de la muerte de Lope de Vega, Rivas Cherif lleva a escena con la compañía del Teatro Español: Fuenteovejuna, El villano en su rincón y La dama boba. En ellas realiza una colaboración importante Federico García Lorca, que aporta un mayor carácter coral a estas comedias de Lope, sobre todo a través de los arreglos musicales. Así por ejemplo, en la Fuenteovejuna, que se presenta el 23 de marzo de 1935, se introduce una antigua danza con arcos, recogida del trabajo investigador del Centro de Estudios Históricos (Torner, Américo Castro, Escudero y Bal y Gay) ${ }^{8}$; a ello hay que sumarle los variados romances y canciones que se incluyen en la representación para ser cantadas y bailadas (Sea bien venido el comendatore, romance popular recogido por Salinas; Al val de Fuenteovejuna; unas seguidillas de Laserna del siglo XVIII para la escena coral de la boda, Vivan muchos años los desposados) (Gil, 2003: 252). El Teatro Escuela de Arte,

8 Son años de investigación y recuperación del acervo cultural popular, con el Centro de Estudios Históricos (1910). Así resurgen de la memoria colectiva la lírica primitiva medieval, los villancicos tradicionales, los romances y los cantares de gesta, anónimos y de naturaleza coral; muchos de ellos introducidos en la escena dramática a través de un coro o un corifeo que representa al pueblo, tal como vemos en el teatro de Lorca y Alberti. 
dirigido por Rivas Cherif, interpreta muchas de estas canciones y bailes que requieren una intervención colectiva. Los estudiantes de la T.E.A. vuelven a ser, como otras muchas veces, el coro en estas representaciones de la compañía de Margarita Xirgu9 (Rodrigo, 1988: 197-204). El resultado es aplaudido por la crítica, que resalta esta disposición escénica de los grupos con sus movimientos rítmicos y de los figurantes, a partir de la escenografía artística de Sigfrido Bürmann. (Espina, 24 de marzo, 1935: 2).

En la reinauguración del Teatro Romano de Mérida, en junio de 1933, la crítica teatral pondera la puesta en escena que ha hecho Rivas Cherif de la Medea de Séneca — con la adaptación de Unamuno-, considerándola muy apropiada para el escenario. Destaca en ella la interpretación colectiva, con sus desplazamientos por el proscenio y la orkhestra. Igualmente, considera acertado el acompañamiento musical y el trabajo de figuración que coadyuva en una presentación coral moderna. Todo ello dará como resultado un espectáculo de arte total, en el que los coros aportan el ritmo escénico y la brillantez visual y musical de la representación (Chabás, 19 de junio, 1933: 6; La Voz, 19 de junio 1933: 3; El Sol, 20 de junio, 1933: 3). El resultado es un teatro coral que integra la acción enérgica de los actores con la participación del público, fundiéndose ambos en un gran coro:

De pronto, mientras el coro comenta sobre un fondo orquestal el furor vengativo de Medea, surge un mancebo aguerrido, que da al aire la noticia del incendio de los palacios del rey. Y un humo espeso y rojo surge detrás del escenario y llena el cielo y le acompañan gritos y rumores y luces de antorchas y correr de esclavos, que forman como un rápido y lamentoso acompañamiento al vibrante monólogo de la protagonista.

9 Con la creación de la Junta Nacional de la Música y Teatros Líricos se busca promover el teatro dramático nacional y para ello se funda el Teatro Escuela de Arte (TEA), dirigido por Rivas Cherif, que tendrá vigencia desde 1930 hasta 1936. Con ella se hace efectiva una pedagogía teatral que integra la declamación, la música y la coreografía en un todo; tal como había visto don Cipriano en los teatros-escuelas de Europa (Teatro de Arte de Moscú, Vieux Colombier de París). Consecuencia lógica de esta enseñanza coreográfica es el auge y protagonismo que adquieren los coros y los grupos escénicos sobre el escenario. Como describía Rivas Cherif, el Teatro Lírico Nacional estaba compuesto por una orquesta y unos coros «selectos de profesión», dirigidos por los maestros Acevedo, Sabina, Estela y Anglada. La mejor prueba de este nuevo enfoque coral de la escena se da ya en el inicio del proyecto, con la representación de La Dolores, de Bretón, en la que la crítica destacó sobremanera la puesta en escena dirigida por Rivas Cherif y Eugenio Casals. Así lo apostilla Díez-Canedo: «La perfección del conjunto, el cuidado de la escena, el movimiento de masas, los mil pormenores que mantienen vivo el fondo en que se mueven los personajes secundarios, los coristas y comparsas» (Aguilera y Aznar, 1999: 296). 
$Y$ en el momento final, cuando arrastrada por las furias mata a sus hijos y en el carro infernal arrebatada por ellas y perseguida por Jasón y sus soldados, es tal la brillantez del conjunto, la rapidez del movimiento, lo acertado de la luz y lo patético de gritos, voces y alaridos, que el público en pie, exaltado, conmovido rompe en aplausos y vítores como nunca se han oído (Lluch, 19 de junio, 1933: 6-7; Gil, 2003: 268-269).

Rivas Cherif reconoce la importancia de los coros en esta puesta en escena de Medea, resaltando el despliegue musical del conjunto que tiene su punto de referencia en la ópera italiana:

LA MÚSICA DE LOS COROS. — ¿Cómo proyecta resolver la participación de los coros?

- De la parte musical se ha encargado Óscar Esplá. Acompañarán la representación comentarios orquestales. Esta se realizará por el sistema que adoptó Claudino Monteverde al representar en su tiempo Orfeo; representaciones aquellas que fueron punto de partida para la ópera italiana. Pretendemos que el coro sea muy sencillo.

Dirán su parlamento en forma salmodiada. Cooperarán en esta empresa la Orquesta Filarmónica y la Masa Coral de Madrid. Una gran fiesta de arte (El Sol, 13 de abril, 1933: 8).

Rivas Cherif también llevó al Teatro Romano de Mérida la Elektra, de Hoffmansthal, en el verano de 1934. Destacaron en ella los grupos escénicos y las comparsas, que intervinieron en gran número y con frecuencia. Teatro coral, con música, danza y la iluminación de unas antorchas, portadas por una comparsa procesional, acompañada por la Marcha Fúnebre del Ocaso de los dioses, de Wagner, como el mismo Rivas Cherif relata (Rivas Cherif, 1991: 247-248).

Con motivo de las fiestas de Navidad de 1932 adapta una selección de textos clásicos para representar en el Teatro Español (el anónimo Auto de los Reyes Magos, el Auto de Navidad, de Juan del Encina y Los pastores de Belén, de Lope de Vega), incluyendo una pieza de su creación, Nacimiento. Durante la representación se intercalaron villancicos, pastorelas, hossanas, romancillos y bailes, con la adaptación del maestro Rafael Benedito, que era profesor de música de la Residencia de Estudiantes - donde apuesta por el coro como recurso didáctico (Benedito, 1934: 31-34) y director del Coro del Conservatorio de Madrid. 


\subsection{El elemento popular}

Rivas Cherif también cree que en la labor renovadora del teatro ha de recuperarse un público popular. Las Misiones Pedagógicas y La Barraca siguieron este propósito, y en ambas el coro estaba presente ${ }^{10}$. Ya en el teatro griego el coro constituía el apéndice del pueblo dentro de la acción dramática, con sus valores y tradiciones. Esta misma idea, de un teatro que retorne a las raíces corales originarias para volver a pertenecer al pueblo, es la que defienden Ramón J. Sender, en Teatro de masas (1931) y Luis Araquistáin, en La batalla teatral (1930). Pero el teatro social en España, en vez de partir de la industrialización, como en Alemania, o de la Revolución, como en Rusia, buscaría su impulso en la tradición popular, con sus canciones y romances. Así lo vieron García Lorca y Rivas Cherif al recuperar el mejor teatro clásico español.

Ya anteriormente Miguel de Unamuno recogió en su ensayo, «La regeneración del teatro español» (1896), la idea del teatro como función social y educativa del pueblo, a través de la diversión. Para ello se fija en el coro como elemento regenerador del teatro, constituyendo la expresión popular del arte a través de diversas manifestaciones que se enraízan en el folclore. Así lo vemos en los cantos y bailes de las fiestas tradicionales, de las bodas o las romerías, representados por coros de campesinos, como aparecen en el teatro rural de Valle-Inclán y García Lorca. Dice Unamuno:

...del pueblo brotó el drama, del coro.

$[\ldots]$

$Y$ hoy parece que quiere resucitar el coro, surgiendo de la multiplicación de personajes, pero coro de integración, no la masa antigua indiferenciada, coro resultante de muchedumbre de protagonistas concordados.

$[\ldots]$

$Y$ a la vez que vislumbramos el advenimiento del coro redivivo y remozado, el teatro mismo, que tomado en amplísimo sentido representa el fondo primero de donde brotaron diferenciándose las artes, y en la literaria la

10 Los miembros del Patronato de las Misiones (creadas el 29 de mayo de 1931), entre los que se encontraban Antonio Machado, Óscar Esplá y Pedro Salinas, creyeron oportuno añadir el coro al teatro, formando así un todo inseparable: «Coro y Teatro del Pueblo». Este incluiría un repertorio musical con canciones populares españolas tal como viene recogido en el Informe (Cabra Loredo, 1992). En el teatro universitario itinerante La Barraca (1932-1936) también el coro ocupaba un lugar importante. Lorca destinaba a una serie de actores para componer dicho coro, entre los que se incluía a veces él mismo, cantando o recitando (Sáenz de la Calzada, 1998: 291; García Lorca, I, 2002: 185). 
épica y la lírica, volverá a reunirlas en poderosa síntesis como tal vez fundirá de nuevo lo profano con lo religioso (Rubio, 1998: 151-175).

Rivas Cherif crea en 1920 el Teatro de la Escuela Nueva siguiendo un teatro popular y social, de gran cuidado artístico, que ya se estaba realizando en Francia (Rivas Cherif, 24 de enero, 1920: 1-2), Alemania y Rusia: «La Escuela Nueva se propone inaugurar en breve un ensayo de teatro social. Es preciso crear aquí el ambiente artístico de las «Fiestas del Pueblo» de París» (Rivas Cherif, 7 de mayo, 1920: 5). El propio director madrileño incluye en la definición de este proyecto el término «teatro popular», poniendo como ejemplo el teatro oficial de los Soviets en Rusia, establecido por Lunatcharsky (Rivas Cherif, 2 de julio, 1920; Sánchez, 1999; 443. Aznar Soler, 1992: 32).

También la recuperación de los clásicos se entroncará con un teatro de alcance popular, que requerirá unas puestas en escena corales, al aire libre (Medea y Elektra en el Teatro Romano de Mérida; El alcalde de Zalamea, Fuenteovejuna, La dama boba en la plaza de toros de Las Ventas, la plaza del pueblo de Fuenteovejuna ante tres mil espectadores, la Alhambra y la Chopera del Retiro de Madrid). Rivas Cherif pretenderá de este modo realizar un teatro coral para la multitud, siguiendo el ejemplo de las representaciones de masas en Alemania y Rusia. Subyace aquí la idea de un teatro del pueblo, más cercano al concepto coral del teatro antiguo: «Porque el teatro ha de ser para la multitud o no ha de ser [...] El teatro de hoy ha de tener aire de la calle y ha de ser para la multitud. Un teatro con savia política y social y en el cual los problemas del individuo estén en íntima relación con la inquietud colectiva de la época» (I., Luz, 15 de noviembre, 1933: 6; Gil, 2003: 223).

De ahí surge también el interés que tiene Rivas Cherif —al igual que Alberti- por la Numancia de Cervantes:

El coro tiene ya en Numancia una representación más viva, netamente realista, que sin subvertir la ley dramática atribuye a la masa, al pueblo, una representación típica en determinados individuos. Dado el carácter eminentemente popular de la defensa numantina contra los soldados de Roma, hubiera sido fácil la insistencia en la atribución representativa a un coral simbólico (Rivas Cherif, 1991: 92).

El pueblo llano vuelve a tener una presencia activa y principal en el proceso teatral y especialmente en la representación. Así lo reconoce Díez-Canedo en su crítica a la puesta en escena realizada por Rivas Cherif de Un enemigo del pueblo (26-VI-1920): 
Puesto en escena por Cipriano Rivas Cherif con muy escasos medios, ofreció, no obstante, una novedad en nuestras costumbres teatrales que dio plena medida de su eficacia. Fue la novedad de dividir la escena del acto cuarto, el del mitin, a ejemplo de lo que se ha hecho en teatros extranjeros, en dos partes: una, el escenario, para los principales actores; otra, la sala, para lo que podríamos llamar «el coro». El supuesto público del mitin estaba distribuido en butacas, palcos, pasillos; en un momento dado, parte de él subía a escena. La novedad era peligrosa, y más lo hubiera sido ante un público viciado de teatro usual. El de obreros que llenaba el Español se dio perfecta cuenta de todo y se sintió envuelto en la acción de manera palpitan (Díez-Canedo, 3 de julio, 1920: 13-15; Aguilera y Aznar, 1999: 94).

\subsection{El elemento ritual}

Los dramaturgos renovadores vuelven a tomar como referencia las representaciones litúrgicas. Simbolistas y expresionistas acuden a un lenguaje teatral ritualizado, cuyos orígenes eran corales. Se produce en estos años un auge de los Autos sacramentales, las Pasiones y los Misterios medievales.

Rivas Cherif retoma también este sentido litúrgico del coro en el teatro, realizando las adaptaciones para el Teatro Español del Auto de los Reyes Magos, el Auto de Navidad, de Juan del Encina y Los pastores de Belén, de Lope de Vega (23-XII-1932). En su libro Cómo hacer teatro encarece la representación del Misterio de Elche - promovida durante la Segunda República por el alicantino Óscar Esplá-, entroncándolo con el rito a Dionisos del teatro griego (Rivas Cherif, 1991: 263-264). A propósito de ello, hace referencia a las puestas en escena de La vida del hombre y Everyman, que realizaron Hofmansthal y Reinhardt en Salzburgo (Rivas Cherif, 1991: 99). El rito y la música conforman el carácter coral de estas representaciones religiosas dramatizadas, que tanto pondera el director madrileño como modelo para un teatro dramático renovador (Rivas Cherif, 1991: 100).

Rivas Cherif reencuentra la afinidad que hay entre la liturgia religiosa y el teatro, tal como le apuntaba Valle-Inclán en una carta (Romera Castillo, 1982: 40-41), volviendo así a su naturaleza coral originaria. Esta convergencia la encuentra en la congregación colectiva del pueblo, convertido en público participativo (Rivas Cherif, 1991: 35). Al igual que García Lorca, también se siente atraído por las fiestas tradicionales del pueblo, de naturaleza coral (desfiles, procesiones, etc...), como demuestra al hablar de la Fiesta de Moros y Cristianos de Alcoy (Rivas Cherif, 1991: 102). 
En el montaje del auto El gran teatro del mundo, presentado en el Teatro Español de Madrid (21-XII-1930), Rivas Cherif realiza una puesta en escena de teatro total que sigue los modelos arquitectónicos de Adolphe Appia y Reinhardt, en donde la distribución de los grupos y coros sobre el escenario, en varias hileras y conjuntos de fondo, configurarán un artístico retablo coral de cuidadísima plástica, que transmite todo el carácter ritual de la obra. Este retablo, al igual que en el coro griego, a veces guarda un quietismo y silencio solemne, pero otras veces se desplaza con movimientos colectivos bien armonizados, interpretando con voces acompañadas de música. Todo este planteamiento orquestal del conjunto escénico es completado con los figurines (Díez-Canedo, 23 de diciembre, 1930: 8). La influencia de Max Reinhardt es evidente en esta puesta en escena de El gran teatro del mundo, de Calderón. No en vano, Rivas Cherif se puso en contacto con el director vienés en su viaje a Alemania de 1933, quien realizó también una versión escénica del auto sacramental calderoniano.

Asimismo, cuando Rivas Cherif habla del proyecto de restauración del Teatro Romano de Mérida muestra un especial interés por todo lo relacionado con el coro, atrayéndole sobremanera su vínculo con los ritos dionisíacos —al igual que a Ortega y Gasset (1982: 27-29, 99-101)—, en los que rito y baile se unen para producir un espectáculo teatral completo (Rivas Cherif, 1991: 108).

\section{REFERENCIAS BIBLIOGRÁFICAS}

AGUILERA SASTRE, Juan (1997). Cipriano de Rivas Cherif: una interpretación contemporánea de Valle-Inclán. Barcelona: Cop d'Idees-T.I.V. AGUILERA SASTRE, Juan y AZNAR SOLER, Manuel (1999). Cipriano de Rivas Cherif y el teatro español de su época (1891-1967). Madrid: Publicaciones de la Asociación de Directores de Escena de España.

AGUILERA SASTRE, Juan; AZNAR SOLER, Manuel y RIVAS, Enrique de (1985). Cipriano de Rivas Cherif. Retrato de una utopía. Madrid: Centro de Documentación Teatral.

APPIA, Adolphe (2000). La música y la puesta en escena. La obra de arte viviente. Madrid: Publicación de la Asociación de Directores de Escena de España.

ARAQUISTÁIN, Luis (1930). La batalla teatral. Madrid: Mundo Latino.

AZNAR NAVARRO, F. (1921, 16 de marzo). «En el Ateneo. Teatro de la Escuela Nueva». La Correspondencia de España 22.977, 3. 
AZNAR SOLER, Manuel (1992). Valle-Inclán, Rivas Cherif y la renovación teatral española (1907-1936). Barcelona: Cop d'idees/T.I.V.

BENEDITO, Rafael (1934). Cómo se enseña el canto y la música. Madrid: Publicaciones de la Revista de Pedagogía.

CABRA LOREDO, M. ${ }^{a}$ Dolores (1992). Misiones pedagógicas. Informes [Texto impreso]: septiembre de 1931-diciembre de 1933. Madrid: El Museo Universal.

CHABÁS, J. (1933, 19 de junio). «Una gran fiesta de arte. La representación de Medea en el Teatro Romano de Mérida». Luz, 6.

- (1933, 17 de noviembre). «Se estrena en el Español Divinas palabras, de Valle-Inclán». Luz, 6.

COPEAU, Jacques (2002). Hay que rehacerlo todo (Escritos sobre teatro). Madrid: Asociación de Directores de Escena de España.

DE LA CRUZ, S. (1935, 21 de junio). «Balance de las cinco temporadas de Margarita Xirgu y Cipriano Rivas Cherif en el teatro Español». Heraldo de Madrid, 7.

DÍEZ-CANEDO, E. (1920, 3 de julio). «La semana teatral. Español: Un enemigo del pueblo». España, 270, 13-15.

- (1930, 23 de diciembre). «El gran teatro del mundo, de Calderón, con el Auto de las donas y Las aceitunas». El Sol, 8.

- (1934, 31 de diciembre). «Yerma, el poema trágico de Federico García Lorca, obtuvo un éxito extraordinario en el Español». La Voz, 3.

DOUGHERTY, Dru y VILCHES, María Francisca (1992). El teatro en España entre la tradición y las Vanguardias. Madrid: CSIC.

- (1997). La escena madrileña entre 1926 y 1931. Madrid: Editorial Fundamentos.

ESPINA, A. (1935, 24 de marzo). «Conmemoración de Lope de Vega. Fuenteovejuna, nueva versión escénica en quince cuadros». El Sol, 2.

FUENTES, Víctor (1980). La marcha del pueblo en las letras españolas. Madrid: Ediciones de la Torre.

GARCÍA LORCA, Isabel (2002). Recuerdos míos. Madrid: Tusquets Editores.

GARCÍA-RAMOS MERLO, Jorge (2012). El coro en el teatro: su resurgimiento como elemento renovador en la escena europea y española del primer tercio del siglo XX. Tesis doctoral inédita, dirigida por María Clementa Millán Jiménez. Universidad Nacional de Educación a Distancia, Facultad de Filología. 
GIL FOMBELLIDA, M. ${ }^{a}$ Carmen (2003). Rivas Cherif, Margarita Xirgu y el teatro de la II República. Madrid: Editorial Fundamentos.

HERNÁNDEZ, Mario (2005). Edición de La zapatera prodigiosa, de Federico García Lorca. Madrid: Alianza Editorial.

- (1979). «Cronología y estreno de Yerma, poema trágico, de García Lorca». Revista de Archivos, Bibliotecas y Museos LXXXII.2 [abriljunio], 304.

LLUCH, F. (1933, 19 de junio). Sparta, 6-7.

MACHADO, Manuel (1934, 15 de abril). La Libertad, 4.

MEYERHOLD, Vsevolod (1998). Teoría teatral. Madrid: Editorial Fundamentos.

- (1992). Textos teóricos, edición de Juan Antonio Hormigón. Madrid: Publicaciones de la Asociación de Directores de Escena.

MILLÁN JIMÉNEZ, María Clementa (1988). Edición de El público, de Federico García Lorca. Madrid: Cátedra.

ORTEGA Y GASSET, José (1966). «Elogio del Murciélago». En El espectador, tomo IV, 123-130. Madrid: Espasa-Calpe.

- (1982). Ideas sobre el teatro y la novela. Madrid: Revista de Occidente / Alianza Editorial.

- (1985). La rebelión de las masas. Madrid: Espasa-Calpe, Col. Austral.

PEDRAZA JIMÉNEZ, Felipe B. (2011). El drama rural. Metamorfosis de un género: la perspectiva española y el contexto internacional. Vigo: Editorial Academia del Hispanismo.

PRATS, A. (1933, 13 de abril). «Medea, arrebatada en carros de aladas serpientes, consumará su fatal destino en el teatro romano de Mérida. La música de los coros». El Sol, 8.

RIVAS CHERIF, Cipriano (1979). Retrato de un desconocido. Vida de Manuel Azaña. Barcelona: Ediciones Grijalbo.

- (1991). Cómo hacer teatro. Valencia: Pre-Textos.

- (1920, 24 de enero). «Desde París. El teatro del pueblo». La Libertad, $1-2$.

- (1920, 28 de febrero). «El tricornio». España 252, 12-13.

- (1920, 7 de mayo). «Las Fiestas del Pueblo. El Himno a la Alegría». La Internacional, 5.

- (1920, agosto). «Divagación a la luz de las candilejas». La Pluma 3, 113-119. 
- Cipriano (1920, 21 de agosto). «Nuevo repertorio teatral.». España $277,11$.

- (1922, 5 de marzo). «La danza clásica y el baile castizo.». Los Lunes de El Imparcial [Aguilera y Aznar, 1999: 143].

- (1928, 9 de mayo). «El Shakespeare del cine». ABC, 10-11.

- (1933, 19 de abril). «Los teatros y sus diferentes servicios escénicos». $E l$ Sol, 1 .

- (1934, 13 de abril). «El alcalde en la arena». Luz, 6.

- (1965, 24 de enero). «El teatro de mi tiempo. El primer reparto de Yerma». El Redondel, 12.

- (1968, 21 de enero). «Autobiografía». El Redondel. [Aguilera y Aznar, 1999: 29].

RODRIGO, Antonina (1988). Margarita Xirgu. Madrid: Aguilar.

ROMERA CASTILLO, José (1982). «Cartas de los Valle-Inclán a Azaña y Rivas Cherif». Los Cuadernos del Norte 12, 40-43. Incluido en su libro, De primera mano. Sobre escritura autobiográfica en España (siglo XX). (Madrid. Visor Libros, 2006, 433-437).

RUBIO JIMÉNEZ, Jesús (1998). La renovación teatral española de 1900: manifiestos y otros ensayos. Madrid: Asociación de Directores de Escena de España.

SÁENZ DE LA CALZADA, Luis (1998). La Barraca. Teatro Universitario, seguido de Federico García Lorca y sus canciones para La Barraca. Madrid: Residencia de Estudiantes / Fundación Sierra Pambley.

SAMPELAYO, C. (1931, 26 de diciembre). «Rivas Cherif. Premio Nacional de Literatura». Heraldo de Madrid, 11.

SÁNCHEZ, José A. (1999). La escena moderna. Antología de manifiestos y textos sobre teatro de vanguardia. Madrid: Akal.

\section{Otros artículos de prensa}

- (1930, 14 de enero). «Bragaglia expone sus teorías acerca del teatro moderno». Heraldo de Madrid, 7.

- (1932, 8 de marzo). «El estudiante en acción. Asociación profesional de alumnos de arquitectura». El Sol, 2.

- (1933, 4 de enero). «El arte en el teatro. Una conferencia de Rivas Cherif». La Libertad, 5. 
- (1933, 1 de marzo). «Cipriano Rivas Cherif, a Alemania». La Voz, 4.

- (1933, 2 de marzo). «El Sr. Rivas Cherif, a Alemania». El Sol, 8.

- A.P. (1933, 13 de marzo). «Desde París. Una breve charla con Rivas Cherif». El Heraldo de Madrid, 5.

- (1933, 19 de junio). «La representación de la tragedia Medea en el teatro Emérita Augusta». La Voz, 3.

- (1933, 20 de junio). «Una representación memorable de la Medea de Séneca, en el teatro romano de Mérida». El Sol, 3.

- I. (1933, 15 de noviembre). «Rivas Cherif dice que hay que hacer un teatro de la calle y para la multitud». $L u z, 6$

- (1935, 1 de junio). «Conversaciones. A propósito de El villano en su rincón». La Voz, 3.

- (1938, 21 de diciembre). «El teatro en la U.R.S.S. El festival de Moscú». La Vanguardia, 3.

Recibido el 2 de abril de 2013.

Aceptado el 19 de septiembre de 2013. 
